\title{
EDUCAÇÃO AMBIENTAL COM ESTUDANTES DO IFMG: FORMAÇÃO DE UM BOSQUE FLOREŞTAL EM SÃO JOÃO EVANGELISTA (MG)
}

Ivan da Costa Ilhéu Fontan ${ }^{1}$

Rosiane Fátima de Almeida ${ }^{2}$

Resumo: O presente relato busca compartilhar informações metodológicas e práticas de uma ação de Educação Ambiental: o plantio de um bosque florestal no Instituto Federal de Minas Gerais em São João Evangelista/MG. O projeto foi desenvolvido em uma área de pastagem em desuso e as atividades desenvolvidas foram: visita in loco para planejamento; roçada mecanizada; demarcação do trajeto da trilha de visitação; controle de formigas cortadeiras; marcação, abertura de covas e adubação de base; plantio, coroamento manual e adubação de cobertura. O trabalho constituiu uma oportunidade única de praticar a Educação Ambiental em um ambiente não formal, estimulando nos estudantes sua capacidade crítica e criativa para superação de adversidades.

Palavras-chave: Educação Ambiental; Bosque Florestal; Sustentabilidade.

Abstract: This report seeks to share methodological and practical information on an environmental education action: the planting of a forest grove at the Federal Institute of Minas Gerais in São João Evangelista / MG. The project was developed in a pasture area in disuse and the activities developed were: on-site visit for planning; mechanized mowing; demarcation of the path of the visitation trail; control of leaf-cutting ants; marking, opening of planting pits and base fertilization; planting, manual crowning and cover fertilization. The work was a unique opportunity to practice environmental education in a non-formal environment, stimulating students' critical and creative capacity to overcome adversity.

Keywords: Environmental Education; Forest Grove; Sustainability.

${ }^{1}$ Instituto Federal de Minas Gerais. E-mail: ivanfontan.florestal@gmail.com. Link para o Lattes: http://lattes.cnpq.br/2851092835077975

2 Instituto Federal de Minas Gerais. E-mail: rosianecontacto@gmail.com. Link para o Lattes: http://lattes.cnpq.br/2311909407411662 


\section{Introdução}

O agravamento dos impactos negativos ao meio ambiente provocados pelos modelos de exploração predatórios dos recursos naturais tem levado a um desequilíbrio na relação do homem com a natureza comprometendo o bemestar e a qualidade de vida de populações ao redor do mundo (MARQUES et al., 2014, p.13; CRUZ, MELO; MARQUES, 2016, p. 184).

O processo de ocupação territorial, a falta de planejamento no uso dos recursos hídricos, a adoção de modelos de exploração agropecuária intensivos, os processos de urbanização e industrialização sem uma gestão ambiental adequada e o aumento da população estão entre as grandes causas da degradação do ambiente, perda na capacidade produtiva dos solos, diminuição da biodiversidade e comprometimento dos recursos hídricos (FONTAN, CARVALHO; GUIMARÃES, 2016, p. 50; REIS et al., 2017, p. 1).

Diante deste cenário torna-se extremamente importante proporcionar à sociedade a oportunidade de refletir sobre esta realidade de desequilíbrio e sensibilizá-la para a necessidade de mudança de atitude diante das questões ambientais (CORREIA, 2012, p. 80; MORAIS, CANEDI; CORTELAZZO, 2015, p.393). Para tal destaque deve ser dado à Educação Ambiental, que pode ser entendida como um processo de construção de valores sociais, conhecimentos, habilidades, atitudes e competências voltadas para a conservação do meio ambiente, garantindo uma relação integradora do homem com a natureza (BRASIL, 1999; POLLI; SIGNORINI, 2012, p. 95).

Dentre os principais públicos de interesse para as ações de Educação Ambiental estão as crianças e jovens, importantes agentes multiplicadores dos preceitos de responsabilidade social e ambiental na sociedade. No município de São João Evangelista, integrante da bacia hidrográfica do rio Suaçuí, formadora da bacia do Rio Doce, considerada uma das mais degradadas do Brasil, existe uma população estudantil (da educação infantil ao ensino superior) de 5.366 alunos (IBGE, 2010), que pode ser contemplada com as mais variadas ações e projetos de Educação Ambiental.

Visando proporcionar um ambiente favorável à reflexão sobre as questões socioambientais no município de São João Evangelista/MG, além de conscientizar um grupo de estudantes do Instituto Federal de Minas Gerais sobre a importância das árvores e da conservação dos ecossistemas naturais, foi desenvolvido um projeto de plantio de um bosque florestal, e nessa perspectiva, pretende-se com esse artigo compartilhar com os leitores as informações metodológicas e práticas envolvidas nesta iniciativa.

\section{Desenvolvimento do Projeto}

O trabalho foi conduzido por um grupo de 7 (sete) estudantes do curso de bacharelado de engenharia florestal do IFMG-SJE durante os meses de setembro a dezembro de 2017 , e constituiu o projeto prático acadêmico da disciplina de "Sistemas e práticas silviculturais". 
A intenção desta proposta de trabalho foi conscientizar os estudantes sobre a importância das árvores e da conservação dos ecossistemas naturais por meio de atividades realizadas em um ambiente não formal de educação. Trabalhos desta natureza proporcionam aos participantes a oportunidade de aplicar conhecimentos teóricos de modo a contribuir com sua formação profissional, além de colaborar com o desenvolvimento socioeconômico sustentável local e regional (FOTAN; REIS; LAGE, 2020, p. 5).

O projeto foi desenvolvido em área do Instituto Federal de Minas Gerais localizado no município de São João Evangelista (IFMG-SJE), situado na microrregião de Guanhães e mesorregião do Vale do Rio Doce. O clima predominante nessa região segundo a classificação de Köppen é do tipo Cwa Tropical Continental com chuvas de verão e inverno seco, com temperaturas máxima e mínima de $26,0 \stackrel{\circ}{\circ} \mathrm{C}$ e $13,5{ }^{\circ} \mathrm{C}$ (médias anuais), respectivamente, e índice pluviométrico médio anual de $1.377 \mathrm{~mm}$.

O bioma predominante na região é a Mata Atlântica, característica que dá ao município uma rica diversidade de fauna e flora com destaque considerável à diversidade de espécies florestais.

O local de plantio do bosque caracterizava-se por ser uma área de pastagem em desuso com presença de poucos indivíduos arbóreos isolados, adjacente ao viveiro de produção de mudas florestais do IFMG-SJE (Figura 1).
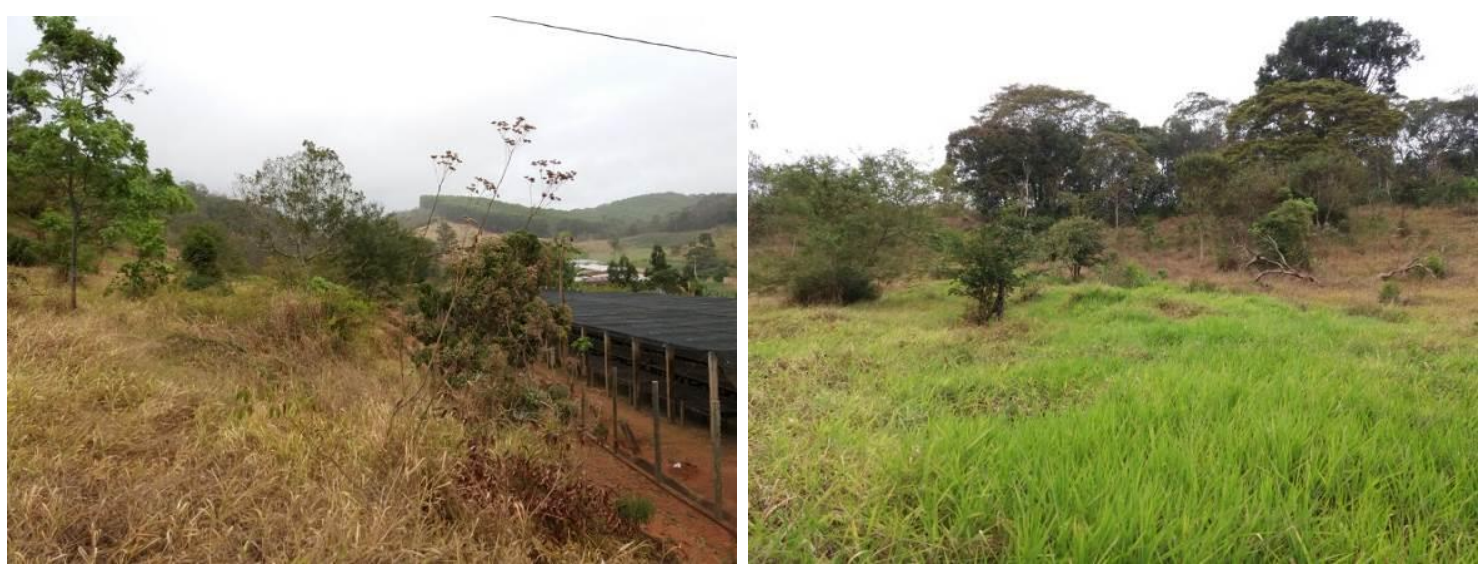

Figura 1: Caracterização geral da área antes da realização das atividades de plantio do bosque florestal, evidenciando a pastagem e a presença de indivíduos arbóreos isolados. Fonte: Os autores (2017).

Além do plantio das mudas florestais propriamente dito para a formação do bosque florestal, o projeto contou ainda com a demarcação de uma proposta de trajeto a ser percorrido na área do bosque, que constituirá uma trilha interpretativa para fins de visitação e ações de Educação Ambiental.

As atividades desenvolvidas no bosque florestal bem como o mês de sua realização podem ser observadas na Tabela 1 apresentada a seguir. 
Tabela 1: Cronograma das atividades realizadas na formação do bosque florestal no Instituto Federal de Minas Gerais, Campus São João Evangelista.

\begin{tabular}{lcccc}
\multicolumn{1}{c}{ Atividade desenvolvida } & \multicolumn{3}{c}{ Mês de realização } \\
& Setembro & Outubro & Novembro & Dezembro \\
\hline $\begin{array}{l}\text { Visita in loco para planejamento de } \\
\text { atividades e delimitação da área. } \\
\text { Roçada mecanizada em área total. }\end{array}$ & $\mathrm{X}$ & & \\
$\begin{array}{l}\text { Demarcação do trajeto da trilha de } \\
\text { visitação do bosque. }\end{array}$ & $\mathrm{X}$ & $\mathrm{X}$ & \\
$\begin{array}{l}\text { Identificação e controle de formigas } \\
\text { cortadeiras. }\end{array}$ & $\mathrm{X}$ & $\mathrm{X}$ & \\
$\begin{array}{l}\text { Marcação dos locais de plantio com } \\
\text { estacas de madeira. }\end{array}$ & & $\mathrm{X}$ & \\
Abertura de covas e adubação de base. & & $\mathrm{X}$ & $\mathrm{X}$ \\
Plantio das mudas. & & & $\mathrm{X}$ \\
$\begin{array}{l}\text { Coroamento manual e adubação de } \\
\text { cobertura. }\end{array}$ & & & \\
\hline
\end{tabular}

Fonte: Os autores (2018).

Durante a visita de planejamento das atividades os alunos percorreram o perímetro do local desejado para o estabelecimento do bosque florestal e com o auxílio de um GPS de navegação determinaram a área disponível para o plantio $(4.179,28 \mathrm{~m} 2)$ e confeccionaram um croqui georreferenciado (Figura 2).

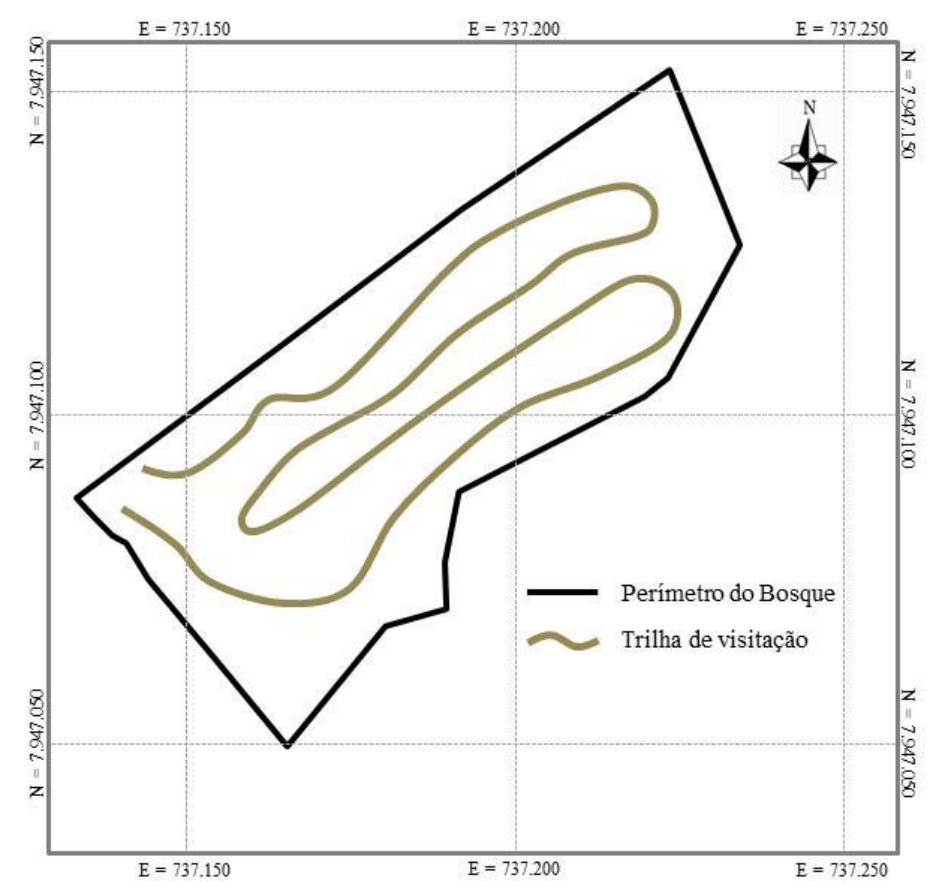

Figura 2: Croqui da área do bosque florestal no Instituto Federal de Minas Gerais, Campus São João Evangelista. Fonte: Os autores (2018). 
Com o intuito de permitir a movimentação adequada e segura dos alunos para a realização das atividades necessárias ao plantio do bosque florestal foi realizada uma roçada mecanizada em área total com auxílio de uma roçadeira acoplada em um trator agrícola, tomando-se o cuidado de desviar dos indivíduos arbóreos já existentes no local, que irão compor o conjunto de árvores do bosque.

Após a roçada, foi possível visualizar melhor a área e propor um trajeto a ser percorrido ao longo do bosque para as futuras visitações e campanhas de Educação Ambiental (Figura 3). A proposta de trilha interpretativa levou em consideração a topografia do terreno que é ligeiramente inclinado, e sua demarcação foi realizada de maneira a minimizar o esforço físico e permitir o acesso a um maior número de usuários/visitantes.
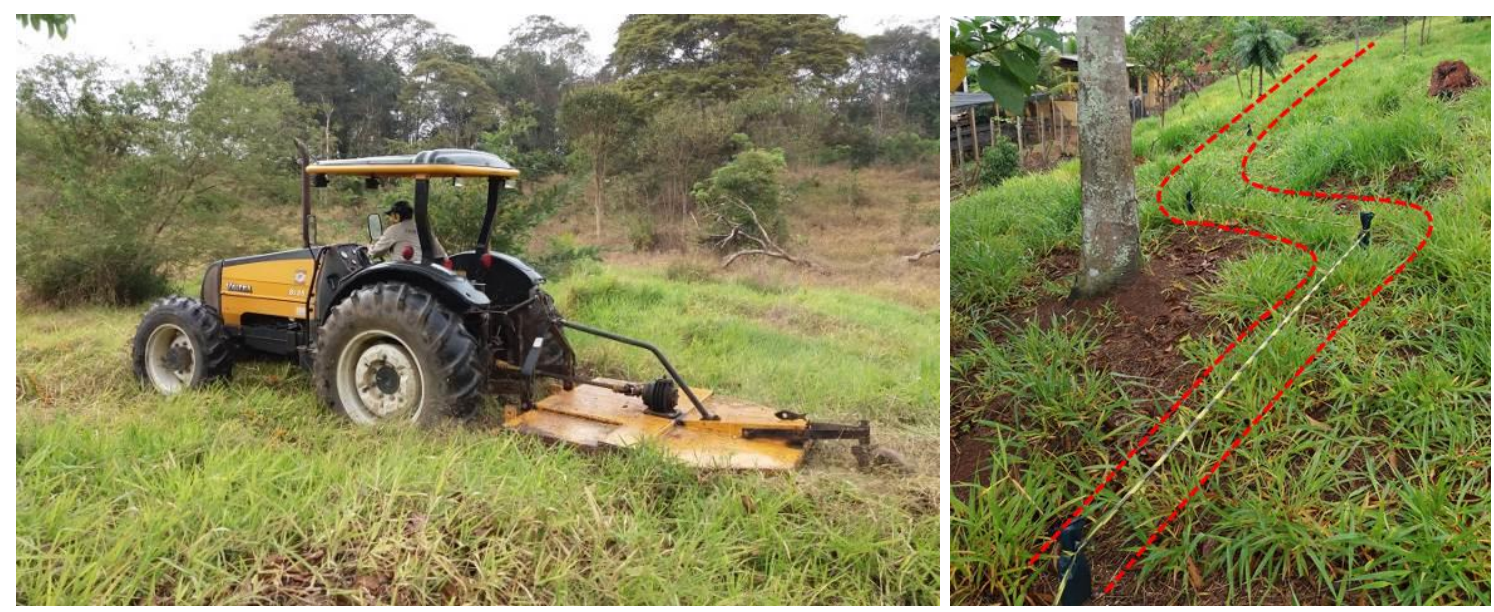

Figura 3: Atividade de roçada mecanizada e demarcação de um trajeto a ser percorrido na área do bosque florestal no Instituto Federal de Minas Gerais, Campus São João Evangelista.

Fonte: Os autores (2017).

Trilhas interpretativas constituem importantes instrumentos no processo de Educação Ambiental por permitirem o contato direto com a natureza e fortalecer vínculos afetivos entre os visitantes e o meio natural (OLIVEIRA; VARGAS, 2009, p. 312). Iniciativas que estimulem o aprendizado no próprio meio natural instigam e sensibilizam os seres humanos a repensar sua visão do mundo e seus hábitos de vida a partir da percepção da realidade ambiental, contribuindo assim para uma redescoberta da sua relação com a natureza, de uma forma mais responsável (ALVARENGA et al., 2018, p. 3).

Antes de se iniciar o período de maior concentração de chuvas foi realizado um controle de formigas cortadeiras por meio da aplicação manual localizada de isca granulada ( $8 \mathrm{~g} / \mathrm{m} 2$ de terra solta) à base de sulfluramida $(0,3 \%$ i.a.) nos ninhos identificados na área do bosque. As formigas cortadeiras, especialmente as saúvas (Atta spp.) podem causar danos significativos aos plantios florestais, especialmente pela desfolha em mudas, que pode retardar seu desenvolvimento inicial ou mesmo levá-las à morte. $\mathrm{O}$ 
uso de iscas granuladas é recomendado para o controle de formigas cortadeiras, pois são de fácil aplicação, apresentam reduzida toxicidade aos seres humanos e ao ambiente e proporcionam alto grau de eficiência de controle (JUREMA, 1980 apud BURATTO et al., 2017, p. 1085).

Após a ocorrência das primeiras chuvas realizou-se a marcação dos locais de plantio com auxílio de estacas de madeira e, posteriormente, os participantes realizaram 0 coroamento manual (remoção das plantas competidoras) e a abertura das covas de plantio com $40 \times 40 \times 40 \mathrm{~cm}$ (Figura 4). O sucesso do plantio de mudas florestais em condições de campo é influenciado pelas condições de aeração, infiltração de água, e umidade do solo, e por esse motivo o preparo do solo tem grande importância e visa criar condições ótimas ao pleno desenvolvimento do sistema radicular das mudas recém plantadas (GONÇALVES, 2002, p. 51; MARCUZZO; ARAÚJO; GASPARIN, 2015, p. 2).
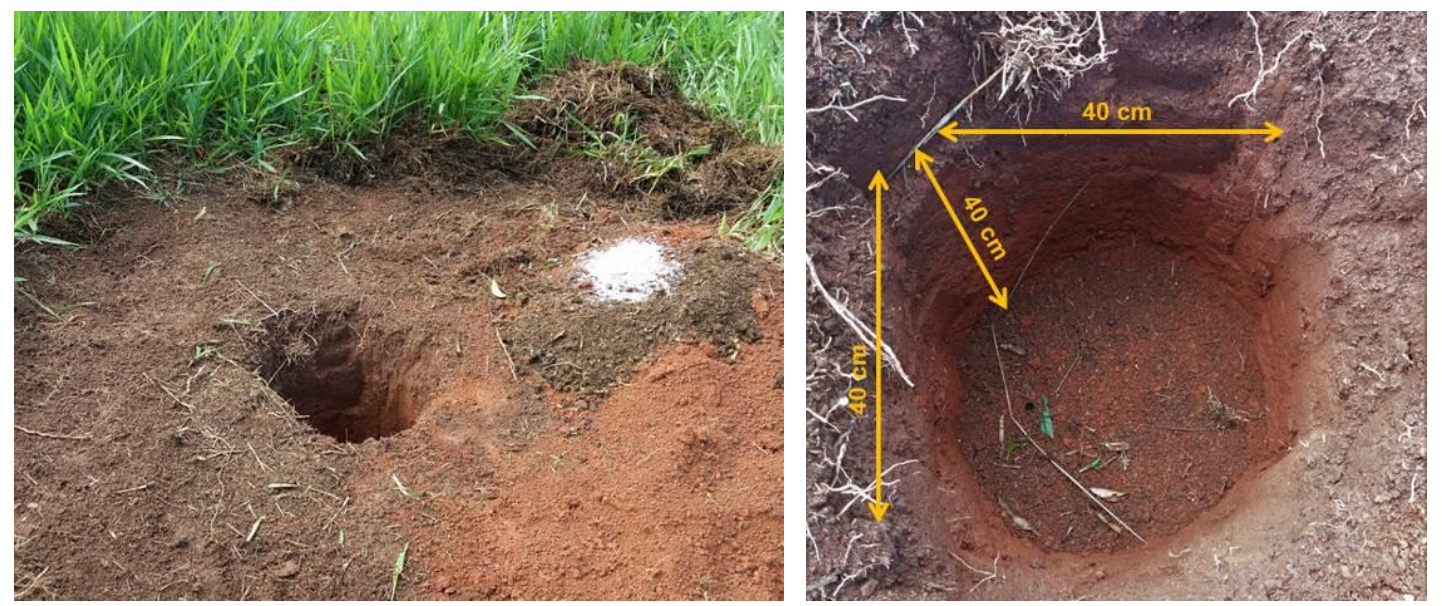

Figura 4: Coroamento e coveamento manual no bosque florestal no IFMG, Campus São João Evangelista. Fonte: Os autores (2017).

Por se tratar de uma área de plantio pequena, com finalidades didáticas, educacionais e contemplativas, não houve uma preocupação exacerbada com a regularidade do espaçamento entre as mudas. A escolha dos locais de plantio das mudas levou em consideração aspectos estéticos, paisagísticos e a necessidade de permitir e facilitar o trânsito de pessoas ao longo do trajeto a ser percorrido no bosque por seus futuros visitantes.

À porção de solo retirada durante a abertura das covas foram misturados cerca de 5 litros de esterco bovino curtido e $150 \mathrm{~g}$ de superfosfato simples por cova. Após a satisfatória homogeneização do solo e dos adubos, a mistura foi depositada nas covas para então receberem as mudas.

O plantio das mudas florestais foi realizado durante dias nublados com temperaturas mais amenas e na iminência de ocorrência de chuvas, para minimizar a necessidade do fornecimento de água via irrigação, melhorar o índice de sobrevivência e o crescimento inicial das plantas. Após o plantio foi 
realizada uma adubação com $200 \mathrm{~g}$ de NKP 4-14-8 por muda, dividindo essa dose em duas faixas laterais, dispostas a uma distância de $20 \mathrm{~cm}$ das mudas (Figura 5).
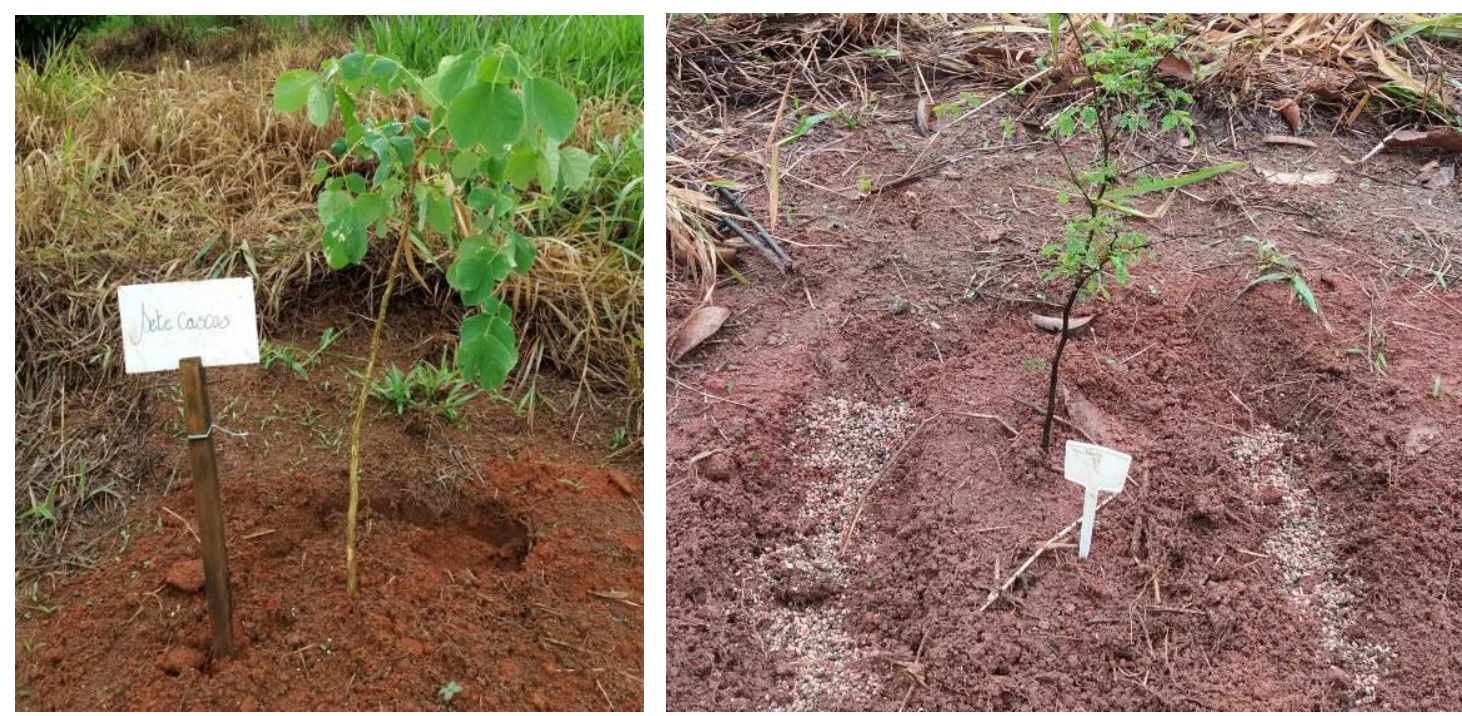

Figura 5: Plantio de mudas e adubação com NKP 4-14-8 no bosque florestal no IFMG, Campus São João Evangelista. Fonte: Os autores (2017).

As espécies florestais utilizadas no plantio do bosque foram selecionadas de acordo com a disponibilidade de mudas no viveiro do IFMGSJE, considerando ainda sua expectativa de crescimento (porte de indivíduos na fase adulta) e aspectos paisagísticos, ecológicos e histórico-culturais. A relação das espécies plantadas no bosque florestal do IFMG-SJE pode ser observada na Tabela 2.

Tabela 2: Relação de espécies utilizadas para a formação do bosque florestal no Instituto Federal de Minas Gerais, Campus São João Evangelista.

\begin{tabular}{lll}
\hline Nome vulgar & Nome científico & Família \\
\hline Acácia Rosa & Cassia grandis L. f. & Fabaceae \\
Araçá boi & Eugenia stipiata McVaugh & Myrtaceae \\
Braúna & Melanoxylon brauna Schott & Fabaceae \\
Copaíba & Copaifera Langsdorffii Desf. & Fabaceae \\
Grumixama & Eugenia brasiliensis Lam. & Myrtaceae \\
Ingá & Inga edulis Mart. & Fabaceae \\
Ipê Mulato & Zeyheria tuberculosa (Vell.) Bureau & Bignoniaceae \\
Ipê Rosa & Handroanthus heptaphyllus (Vell.) Mattos & Bignoniaceae \\
Ipê Roxo & Handroanthus impetiginosus (Mart. ex DC.) Mattos & Bignoniaceae \\
Jatobá & Hymenaea courbaril L. & Fabaceae \\
Jenipapo & Genipa americana L. & Rubiaceae \\
& & Continua...
\end{tabular}


...continuação.

\begin{tabular}{lll}
\hline Nome vulgar & Nome científico & Família \\
\hline Mamão Jaracatiá & Jacaratia spinosa (Aubl.) A. DC. & Caricaceae \\
Mogno & Swietenia macrophylla King & Meliaceae \\
Paineira & Ceiba speciosa (A. St.-Hil.) Ravenna & Malvaceae \\
Pau Brasil & Caesalpinia echinata Lam. & Fabaceae \\
Pau Ferro & Caesalpinia férrea Mart. & Fabaceae \\
Peroba Rosa & Aspidosperma polyneuron Müll. Arg. & Apocynaceae \\
Sapucainha & Carpotroche brasiliensis (Raddi) A. Gray & Flacourtiaceae \\
Tamarindo & Tamarindus indica L. & Fabaceae \\
Tento Carolina & Adenanthera pavonina L. & Fabaceae \\
Uvaia & Eugenia pyriformis Cambess. & Myrtaceae \\
\hline
\end{tabular}

Fonte: Os autores (2017).

\section{Conclusões}

O plantio do bosque florestal constituiu uma oportunidade única de praticar a Educação Ambiental em um ambiente não formal de ensino, estimulando nos estudantes sua capacidade crítica e criativa para a superação das adversidades ocorridas no decorrer do projeto.

Iniciativas como a descrita aqui são de grande importância na formação dos futuros profissionais da área florestal e ambiental, que certamente estarão mais bem preparados para atender as demandas do mercado e da sociedade em geral, de forma mais ética e humanística.

Além disto, o município de São João Evangelista poderá contar com um novo espaço destinado à reflexão da sociedade sobre sua relação com a natureza, e sensibilizá-la da necessidade de mudanças de hábitos e atitudes para a promoção da melhoria da qualidade de vida das atuais e futuras gerações.

\section{Agradecimentos}

Ao Instituto Federal de Minas Gerais, Campus São João Evangelista por permitir e apoiar o plantio do bosque florestal em suas dependências.

Aos estudantes e futuros colegas de profissão Alisson, Aparecida, Carlos Henrique, Carolaine, Rogério, Rosiane e Sarah, pela dedicação e por tornarem realidade o sonho do bosque florestal. 


\section{Referências}

ALVARENGA, C. A.; OLIVEIRA, C. M. V.; FERREIRA, A. L. R.; SILVA, P. B. S.; GREGÓRIO, F. S. F.; CESAR, G. C. L; RIBEIRO, L. A. Trilha interpretativa para promoção da Educação Ambiental na Funcesi, Itabira Minas Gerais. Research, Society and Development, Itabira, v. 7, n. 1: p. 01-19, 2018.

BRASIL. Lei № 9.795, de 27 de abril de 1999. Dispõe sobre a Educação Ambiental, institui a Política Nacional de Educação Ambiental e dá outras providências. Disponível em: <http://www.planalto.gov.br/ccivil 03/ LEIS/I9795.htm>. Acesso em: 10 abr. 2018

BURATTO, D. A.; SOUZA, N. J.; SOUZA, M. D.; ROLIN, F. A. Resistência de iscas granuladas, distribuídas a granel e em microporta-iscas, à ação da umidade em plantios de Pinus taeda no planalto sul-catarinense. Ciência Florestal, Santa Maria, RS, v. 27, n. 3, p. 1083-1093, jul.-set., 2017.

CORREIA, C. J. S. O projeto sala verde em União dos Palmares/AL: possibilidades e desafios de um centro de referência em Educação Ambiental. Ambiente e Educação, Rio Grande, v. 17, n. 2, p. 79-92, 2012.

CRUZ, C. A.; MELO, I. B. N; MARQUES, S. C. M. A Educação Ambiental brasileira: história e adjetivações. Revbea, São Paulo, v. 11, n.1, p. 183-195, 2016.

FONTAN, I. C. I.; REIS, G. M. P.; LAGE, P. Capacitação de agente multiplicador para assistência técnica e extensão rural em viveiros florestais. Revista UNIFESO - Humanas e Sociais, Teresópolis/RJ, v. 5, n. 2, p. 4-16, 2020.

FONTAN, I. C. I.; CARVALHO, A. H. O.; GUIMARÃES, E. C. S. Relatos de Experiências: a Sala Verde Caparaó e a Educação Ambiental não formal. Revista UNIFESO - Humanas e Sociais, Teresópolis/RJ, v. 2, n. 3, p. 46-66, 2016.

GONÇALVES, J. L. M. Conservação do solo. In: GONÇALVES, J. L. M.; STAPE, J. L. (Ed.) Conservação e cultivo de solos para plantações florestais. Piracicaba: IPEF, p. 47 - 129, 2002.

INSTITUTO BRASILEIRO DE GEOGRAFIA E ESTATÍSTICA - IBGE. Censo 2010. Disponível em: <https://censo2010.ibge.gov.br/>. Acesso em: $01 \mathrm{dez}$. 2019.

MARCUZZO, S. B.; ARAÚJO, M. M.; GASPARIN, E. Plantio de espécies nativas para restauração de áreas em unidades de conservação: um estudo de caso no sul do Brasil. FLORESTA, Curitiba, PR, v. 45, n. 1, p. 129-140, jan./mar. 2015.

MARQUES, M. L. A. P.; SILVA, A. F.; ARAÚJO, J. E. Q.; QUEIROZ, T. H. S.; ALMEIDA, I. D. A.; MARINHO A. A. A Educação Ambiental na formação da consciência ecológica. Cadernos de Graduação, Maceió, v. 1, n. 1: p. 11-18, 2014. 
MORAIS, J. L.; CANEDI, P. L. R.; CORTELAZZO, I. B. C. Educação Ambiental na prática pedagógica de professores participantes de um curso de extensão em Educação Ambiental, modalidade blended learning Rev. Eletrônica Mestr. Educ. Ambient, Rio Grande, v. 32, n.2: p. 380-396, jul./dez. 2015.

OLIVEIRA, T. L. F.; VARGAS, I. A. Vivências integradas à natureza: Por uma Educação Ambiental que estimule os sentidos. Rev. eletrônica Mestr. Educ. Ambient., Rio Grande, v. 22: p. 309-322, jan/jul. 2009.

POLLI, A.; SIGNORINI, T. A inserção da Educação Ambiental na prática pedagógica. Ambiente \& Educação, Anápolis, 17(2): p. 93-101, 2012.

REIS, D. A. et al. Influência dos fatores ambientais e antrópicos nas águas superficiais no rio Matipó, afluente do rio Doce. REGA, Porto Alegre, v. 14:p. 115, jan/dez 2017. 